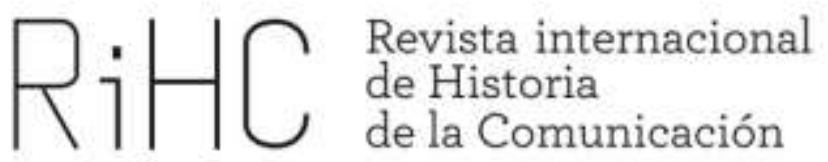

\title{
LA ANDALUCÍA: LA VISIÓN DE UN DIARIO REPUBLICANO SOBRE LA FIGURA DE PRIM (1868-1871)
}

DOI: http://dx.doi.org/10.12795/RiHC.2016.i07.02

José Enrique Lorite

Universidad de Sevilla

jeloriteluque@gmail.com

Recibido: 17-10-2016

Aceptado: 27-11-2016

Resumen: El objetivo de este artículo es el de hacer una aproximación a la imagen que un diario republicano destacado dentro del ámbito periodístico sevillano realizó sobre la figura del general Prim, uno de los indiscutibles protagonistas de la etapa conocida como Sexenio Democrático. Se ha elegido La Andalucía porque se convierte durante la época analizada en el más combativo de los existentes, además de un claro defensor de la república, forma de gobierno contraria a la que defendería Prim.

Palabras clave: prensa, revolución, Prim, España, sexenio

Abstract: The article aim is to make an approach to image that a remarkable Republican newspaper in the journalistic field Sevillian made about the figure of General Prim, one of the undisputed stars of the stage know as Democratic six years. La Andalucía was chosen because it becomes during the period analyzed in the most combative of existing, as well as a clear defender of the republic, form of government contrary to the position defended by Prim. 
Keywords: press, revolution, Prim, Spain, six years

\section{Introducción}

El periodo denominado Sexenio Democrático, surgido tras el exilio de la familia real española a Francia, es un compendio de episodios que marcaron profundamente el devenir de España en los años siguientes, tanto que incluso su influencia se extendió más allá de la etapa en la que se enmarca este capítulo. Comenzado en septiembre de 1868, esta época se caracterizó por importantes cambios y por los continuos enfrentamientos entre los partidos políticos que se encontraban en activo por aquel entonces, sucediéndose por aquellos años una "exploración de distintas posibilidades de organización política" (Artola, 1975: 280). Pero también se produjeron graves choques entre varios bandos, como lo fue la tercera guerra carlista, que comenzó en 1872 y que se prolongaría hasta cuatro años más tarde. Además, los ecos de las voces independentistas de Cuba anunciaban una inestabilidad tal que vendría a empeorar la situación por la que atravesaba el país poco antes del comienzo del último tercio del siglo XIX. Las desavenencias fueron numerosas y su división en distintos apartados, los cuales podríamos dividir en cuatro secciones: la primera de ellas, la del Gobierno provisional, durando desde 1868 hasta 1871; la segunda, protagonizada por el reinado de Amadeo I, prologándose hasta principios de 1873; la tercera, con la República Federal, abarcando hasta enero de 1874, y la República unitaria o Dictadura de Serrano, finalizando en diciembre de 1874 con el pronunciamiento del general Arsenio Martínez Campos en Sagunto, apoyando la restauración de la monarquía borbónica en la figura del hijo de Isabel II, es decir, Alfonso XII.

En cuanto a los partidos políticos, una fragmentación destacable advertía ya de que no sería fácil gobernar por aquel entonces. Principalmente, destacaban los unionistas, encabezados por Serrano; los progresistas, comandados por el general Prim y, tras el asesinato de este, por Sagasta y Ruiz Zorrilla; los demócratas monárquicos, conocidos como "cimbrios", de cuyo partido era representante Cristino Martes y Nicolás María Rivero; y los republicanos federales, cuyos líderes fueron Estanislao Figueras, Francisco Pi i Margall, Nicolás Salmerón y Emilio Castelar. También habría que destacar la presencia del Partido Moderado, con Antonio Cánovas del Castillo a la cabeza, principal artífice de la restauración.

Todo este marco vendría a ser como "un breve período dotado de una viva originalidad en el contexto de nuestra historia contemporánea" (Jover, 1968: 15), centrándonos en este artículo en la figura de Juan Prim. Aunque desde su infancia demostró una importante inclinación por el aspecto militar (Giménez y Guited, 1860: 8), pasaría a la historia como promotor de la llegada de un nuevo rey a España 
restituyendo de este modo la monarquía en el país. Prim, nacido en 1814 en Reus, se convertirá en una de las figuras más importantes del siglo XIX, aumentando su popularidad los últimos años de su vida. Integrado en sus inicios en el Ejército para defender el trono de Isabel II y atraído por las ideas liberales, apoyaría a los progresistas durante el trienio esparterista. En la década de los cincuenta se integraría en la Unión Liberal pero, tras varios enfrentamientos, regresa a las filas progresistas. Será entonces cuando comience a ejecutar varios planes para acabar con el derrocamiento del gobierno moderado, teniendo lugar un fracasado desembarco en Valencia en 1865 y la sublevación del cuartel de San Gil el año siguiente. Destronada la reina tras "La Gloriosa", entraba en la capital vitoreado por el pueblo. Finalmente, se erigiría como principal defensor de la candidatura del duque de Aosta para ocupar el trono español. Entre sus cargos, fue diputado en las Cortes Generales de España desde 1841 hasta 1869, además de Gobernador de Puerto Rico desde 1847 hasta 1848. Posteriormente, ostentó el ministerio de guerra desde el 8 de octubre de 1868 hasta el 27 de diciembre de 1870. Sin embargo, su cargo más importante fue el de presidente del Gobierno, cargo que desempeñó desde el 18 de junio de 1869 hasta el 27 de diciembre de 1870, fecha de su muerte. Prim, antes de estas últimas fechas, ya dejaría reflejada su postura tras ser el artífice del Pacto de Ostende, considerado como el origen de "La Gloriosa".

La prensa, instrumento fundamental a la hora de influir en la opinión pública, comenzaría a centrarse en su figura paulatinamente a medida que iba aumentando el interés del conde de Reus por encontrar una figura que supliera la ausencia en el trono desde la marcha de la familia borbónica. Aunque existían altas tasas de analfabetismo (Pizarroso, 2010: 46-47), es innegable la contribución que la prensa realizó en la formación de una ciudadanía que veía con asombro los numerosos cambios que se sucedían en tan poco tiempo. Durante este tiempo se vivió una explosión de cabeceras en las ciudades más importantes de la época, aumentando sobre todo las de carácter político (Arias, 1995: 41). Sin embargo, y debido a las distintas leyes que se promulgaron, algunas más intransigentes que otras, el número de periódicos fue variando a lo largo de todo el citado sexenio. Habría que sumar también las multas así como la inseguridad, hechos que propiciaron el cierre de redacciones y la desaparición de no pocas cabeceras donde tuvieron cabida las más diversas ideologías políticas.

\section{Objetivo y Metodología}

El objetivo de este trabajo es dar a conocer cómo es la imagen que el diario La Andalucía muestra de Juan Prim, del que en diciembre de 2016 se cumplen 102 años de su nacimiento, figura clave del Sexenio Democrático. Para tal efecto se ha escogido 
uno de los diarios más representativos de esta etapa. Esta elección se basa en la influencia que la cabecera ejerce, ya que nos encontramos ante uno de los más importantes ejemplos del periodismo sevillano, si nos atenemos a la larga duración que tuvo, bastante difícil en un campo donde las transformaciones eran constantes. La Andalucía comenzó su andadura el 31 de diciembre de 1857, contando con la presencia de Francisco María Tubino, director y propietario de este medio. El periódico se presentaba en sus inicios como "defensor de liberalismo, de la familia y de los derechos públicos" y declaraba que "pertenece al partido medio, al partido liberal y de orden, a la monarquía constitucional". Durante el sexenio, daba ahora un paso hacia el frente abrazando el republicanismo, defendiendo con ahínco esta forma de gobierno, aunque defendiendo que era un "periódico liberal independiente" subtítulo que ya se encontraba en 1864 en su cabecera. Llegó a convertirse en uno de los más leídos y entre sus defensas también se encontró la de una unión de las provincias andaluzas, extendiéndose más ampliamente hacia una alianza mayor, la Unión Bético Extremeña, con el fin de conformar un frente sobre las instituciones centrales (Arias, 1987: 384). Finalmente, desaparecería el 29 de diciembre de 1897.

La metodología escogida que se sigue a lo largo de este análisis es la investigación en profundidad de los editoriales seleccionados de este diario, cuyos ejemplares se encuentran depositados en la Hemeroteca Municipal de Sevilla. Pretendemos realizar un acercamiento a la figura de Juan Prim a través de esta cabecera, señalando los principales aspectos que destaca uno de los diarios más representativos del sexenio en la capital hispalense, de modo que podamos conocer las ideas que La Andalucía manifiesta. Así pues, para poder construir con una base sólida una aproximación hacia, en este caso, la imagen de Prim, hay que profundizar especialmente desde septiembre de 1870 hasta principios de 1871, espacio temporal donde las menciones hacia el conde de Reus se incrementan, aumentando cuando se conoce quién ocuparía el trono español, en una época donde además se había celebrado meses antes un congreso en Barcelona promovido por las secciones españolas de la AIT, la Asociación Internacional de Trabajadores, (Lorenzo, 1969: 11), las cuales se extendían con rapidez, sobre todo la de Madrid (Bookchin, 2001: 53). Sin embargo, el punto de partida es anterior a 1870, precisamente en 1868, el mismo día del estallido de "La Gloriosa", para ir conociendo no solo la orientación de la cabecera hacia el republicanismo sino para analizar la figura de Prim desde esta fecha hasta su muerte.

Aunque las referencias son abundantes a medida que nos acercamos a la llegada de Amadeo de Saboya a España, nos hemos propuesto seleccionar aquellas que dan una imagen más representativa del mismo sin necesidad de entrar en reiteradas visiones que nada aportarían a la realización de esta investigación. Son los números relativos al 4 de octubre de 1868; 19 y 20 de septiembre de 1869;13, 19, 20 y 25 de octubre de $1870 ; 2,6,15,17,20$ y 24 de noviembre del mismo año; 24 de diciembre también de la misma etapa; 3 de enero de 1871. 


\section{De "La Gloriosa" al Gobierno provisional: el marco histórico}

El general Juan Prim se convierte en uno de los protagonistas de esta etapa incluso antes de que comenzara "La Gloriosa". Precisamente en agosto de 1866 se firma el Pacto de Ostende, en esta localidad belga, siendo este el principal promotor de una iniciativa donde participarían el Partido Progresista y el Partido Demócrata, añadiéndose posteriormente la Unión Liberal, que lo haría a principios del mismo año en el que estalló la revolución.

Sin embargo, para conocer la figura de Prim hemos de centrarnos en los meses previos antes de la llegada de Amadeo de Saboya, el nuevo rey que vendría a reinstaurar la monarquía pero en una Casa Real distinta a la anterior. Tras la marcha de los Borbones a Francia, se inicia un cambio de rumbo que tendrá consecuencias tanto en el ámbito político como en el social. Posteriormente se abordaría el tema de la búsqueda de un nuevo soberano que trajera de nuevo la monarquía como forma de gobierno a España. La prensa nacional irá decantándose por las diversas personalidades que se barajarán para tal efecto, viviéndose desencuentros entre las cabeceras que defienden a quien creen que será el mejor candidato para ocupar el solio, vacante desde la marcha de Isabel II. Será esta una tónica que comenzará a ser habitual desde el momento en el que la monarquía como forma de gobierno centre el debate en las Cortes los meses previos a la promulgación de la Constitución de 1869, sin duda la más avanzada de las que estuvieron en vigor en la España decimonónica (Varela, 2006: 209).

En Sevilla también se continuará la tónica de que los diarios se erijan como defensores de quien en un futuro puede llegar a ceñirse la corona real. Es el caso de El Oriente, el cual se encargaba de refrendar a Carlos de Borbón, o de La Revolución Española, que se alzaba como portavoz del duque de Montpensier, quien había residido en Sevilla junto con su mujer, la infanta María Luisa de Borbón, en el palacio de San Telmo. Por otra parte, El Porvenir dedicada amplios artículos destacando que el general Espartero sería quien mejor podría convertirse en el futuro rey de España. Distinto era el caso de La Andalucía que, como órgano de ideología republicana, abogaba por este sistema, entendiendo que debía implantarse en un futuro próximo. Sin embargo, Amadeo de Saboya no contaba con un órgano en Sevilla que defendiese su postulación para convertirse en el nuevo monarca de la nación española. La trayectoria de los demás candidatos era de sobra conocida en España, por lo que el reflejo de los mismos en las páginas venía de lejos, mientras que de Amadeo apenas encontramos algunas referencias que distan bastante de los demás si nos atenemos a parámetros de cantidad.

Sin duda, la imagen de Juan Prim no puede desligarse de la importancia que Amadeo de Saboya despierta en las cabeceras, hecho que podemos contemplar también si nos 
centramos en las que tienen como sede la ciudad de Sevilla. Existen referencias al general prácticamente desde el inicio del Sexenio Democrático, pero los periódicos irán centrándose en él a medida que las noticias sobre el futuro Amadeo I vayan llenando sus páginas. Por lo tanto, para entender cómo la prensa, en este caso la hispalense, y más concretamente La Andalucía, aborda la imagen de Prim, hay que acudir irremediablemente a los artículos que versan sobre el duque de Aosta, ya que es en estas líneas donde encontramos referencias destacables que nos den una idea de qué aspectos abordan sobre Juan Prim. Anterior a esta etapa, las menciones al conde de Reus pasarán prácticamente desapercibidas o contendrán solamente alguna referencia no lo suficientemente consistente para poder conformarnos una idea sobre la percepción que la cabecera tiene sobre el citado presidente. En líneas generales, se referirá al partido del que él es militante. Por tanto, el principal defensor de Amadeo de Saboya irá cobrando importancia a medida que se acerque la llegada del futuro rey a Cartagena, para su posterior traslado a la corte madrileña.

Teniendo en cuenta el escaso número de páginas de los diarios de la época, cuatro, incluyendo una de anuncios y datos sobre agricultura, poco margen existe para abordar en profundidad la imagen de cualquier personalidad, máxime si tenemos en cuenta el interés que despiertan las noticias internacionales, que suelen ocupar la primera página.

Esta nueva etapa será crucial para el ámbito periodístico, donde el protagonismo máximo se encontrará en la prensa liberal, con sus diversas concreciones partidistas (Arias, 2001: 172). Según Juan Luis Guereña (1982: 86), en Sevilla, existían 16 títulos en 1867, 15 en 1868, 19 en 1869, 18 en 1970 y, a finales de la década, 15. Principalmente destacarán los dos más leídos, El Porvenir (1848) y La Andalucía (1857). En la década de los sesenta verá la luz El Independiente. Competirán con ediciones locales de periódicos madrileños, como lo fueron El Universal y Las Novedades, guerra que aumentará debido a la gran explosión de cabeceras. El mismo día de la batalla de Alcolea aparecerá El Demócrata, de corta duración, pues en marzo de 1869 deja de publicarse. La Prensa Libre, El Puente de Alcolea y El Círculo Liberal, comenzarían a finales de año, no teniendo noticias de ellos en años siguientes, excepto del último, que aguantó hasta 1869. Probablemente la publicación de más éxito en esta época sería La Revolución Española, en pie hasta 1873, pasando a denominarse después EI Español. Esta explosión de cabeceras se debe a diversos factores. Uno de ellos tiene como protagonista a la Junta revolucionaria de Sevilla, la cual defendía la libertad absoluta de imprenta, sujeta a las penas que por aquel entonces marcaba el Código por los delitos de injuria y calumnia (Rubio, 1985: 97), aspecto que defendía el resto de las Juntas. De vital importancia sería el Decreto-Ley aprobado por el Gobierno el 25 de octubre, donde se defendía el derecho de los ciudadanos a emitir libremente sus pensamientos por medio de la imprenta. Finalmente, en la Constitución de 1869 se recogería este derecho en el artículo 17. 
En lo que respecta a la economía, el país se veía inmerso en un preocupante retroceso. La suspensión de pagos de la Sociedad Catalana de Crédito agravaría la situación, originándose además una cautela tras el hecho acaecido, lo que desataría una crisis más acuciante que en el resto del viejo continente. A esto hay que añadir el endeudamiento del Estado por la "política de prestigio" del gobierno de O’Donnell y la pérdida de crédito exterior en 1865-1866. Por otro lado, afectaba también la quiebra del banco Overend Guerney Co. de Londres, que en España se traduce con retirada de capitales, provocando todo ello quiebras o suspensiones de pagos. Todo este panorama empeoraba además con la aparición de las sequías, ya que si tenemos en cuenta el marcado carácter agrario de la economía era inevitable que acentuaran aún más esta caída (Domínguez León, 1985: 133). Mientras que en el resto de potencias europeas la Revolución Industrial introducía cambios en la producción, en España todavía primaba la deendencia de las estructuras agrarias tradicionales. En lo que respecta a la capital hispalense, en 1865 existían 19 entidades bancarias. Sin embargo, el Crédito Comercial acabaría precipitándose en una caída sin antecedentes y arrastraría con él al Banco de Sevilla, cundiendo la desconfianza entre quienes depositaban sus ganancias en los bancos (Guichot y Parody, 1885: 252).

\section{La Andalucía y el año de 1868}

El verano de 1868 iba caldeando el ambiente para lo que podría suceder de un momento a otro. Los ánimos estaban crispados y sería en septiembre, concretamente el día 18 del citado mes, cuando se produciría el estallido. Prim llegaría a la bahía de Cádiz desde Inglaterra y Serrano haría lo mismo desde las islas Canarias. El almirante Topete se uniría a ellos reforzando este levantamiento, que supondría el inicio del conocido como Sexenio Democrático. Sin embargo, ya desde el principio se adivinaban las discrepancias entre ellos. Serrano prefería que ocupase el trono el duque de Montpensier, Topete se decantaba por Luisa Fernanda y Prim tenía intenciones de que llegase al solio español un rey extranjero (Comellas, 1999: 337). Además, el general ya había protagonizado algunas intentonas entre 1864 y 1868 que, aunque fracasaron, sirvieron para hacer publicidad de las intenciones de Prim y así poder ganar nuevos adeptos para cuando acaeciera la próxima oportunidad (Bolaños, 2014: 32).

Desde este momento se producen en los periódicos diversas interpretaciones sobre este acontecimiento, encontrándonos posturas diametralmente opuestas como son la de diarios tan conocidos como La Época, defensor de la monarquía en la figura de la familia real borbónica, o el periódico del que nos ocupamos en este análisis que abrazaba la República como la única forma de gobierno posible. Para las cabeceras republicanas era más que palpable la admiración que sentían por aquellos que habían 
provocado el inicio de un capítulo que posteriormente se convertiría en una consecución de disputas y problemas que desarrollarían una serie de acontecimientos que irían produciéndose casi atropelladamente. La Andalucía era, junto con el semanario satírico El Clarín, los más representativos diarios republicanos de esta época en Sevilla, y celebraban que la familia real se hubiera marchado de España. En uno de sus artículos propios, hablaba sobre el Palacio Real, el cual había ya quedado vacío y era una "residencia de la corrompida corte y del ominoso gobierno derrocado" (4 de octubre de 1868, p. 2). Era sin duda un motivo de celebración para los más contrarios a la monarquía, que llenaban las páginas alabando este acontecimiento donde el levantamiento de Cádiz ocupaba un remarcable lugar. Ahora, con la libertad existente, los periódicos defenderían abiertamente sus ideas.

El diario La Andalucía continuaba escribiendo sobre este acontecimiento y lo que supondría posteriormente, creyendo que volverían a conquistarse las libertades mutiladas años atrás. Sin embargo, más que dirigir su mirada hacia Prim, Serrano o Topete, ensalzaba la figura del pueblo, a quien aconsejaba además mantener la calma. Sin duda, detrás del triunfo logrado en septiembre de 1868 se encontraban estas tres personalidades políticas y militares, que serían consideradas como héroes por todos aquellos órganos que esperaban la caída de la familia real, y la restitución de la libertad en sus diversas facetas, como la de imprenta, que tan de lleno afectaba a una actividad periodística, resentida durante los últimos tiempos. Esta profesión había sufrido la imposición de multas, algunas de ellas de tal envergadura que hacía imposible el pago por parte de la redacción afectada, finalizando con el cierre de la misma.

El interés por la figura de Prim subiría un peldaño cuando Serrano, quien presidía la regencia, cede la presidencia al general. Fue este un movimiento que no fue bien visto por algunos partidos políticos, dando pie a la entrada de los demócratas monárquicos al gobierno (Martí Gilabert, 2007: 14).

\subsection{La búsqueda de un rey}

El grito que el general Juan Prim diera el 18 de septiembre de 1868 parecía apagarse por momentos. Uno de estos acontecimientos sucedería en noviembre de ese mismo año con el manifiesto de los "cimbrios", centrándose la prensa republicana en algunos de los promotores del citado proyecto. Durante esta época la figura de Prim no se vería salpicada directamente por las críticas de La Andalucía, sobre todo porque este diario dirige sus observaciones hacia los otros periódicos que tenían su sede en la ciudad de Sevilla y que defendían a otros pretendientes, tales como El Porvenir con Espartero, La Revolución Española con el duque de Montpensier y El Oriente, máximo defensor del carlismo en la capital hispalense. 
El diario republicano La Andalucía comenzaba un camino de rechazo hacia la llegada de Amadeo de Saboya que se prolongaría incluso durante la estancia del duque de Aosta en el trono español. Por lo pronto, escasas referencias a él. Sin embargo, expresar su descontento por la forma de gobierno monárquica tras la marcha de Isabel II, intuía ya una repulsa a cualquier familia real que llegase a España. De Amadeo I se encontraban por ahora pocas menciones, hecho constatable propiciado en gran parte por el desconocimiento en profundidad de su figura. Sin embargo, su principal valedor sí comenzaba a despertar interés entre los diarios y era objeto de críticas, prácticamente por todos los que tenían su sede en Sevilla, aunque por distintas razones. Mientras que El Oriente, La Revolución Española y El Porvenir, lo hacían porque el elegido al solio no había sido el que ellos habían defendido, La Andalucía vertía sus observaciones por el hecho de ser contrario a la monarquía, independientemente de la familia que se encontrara al frente.

En septiembre de 1870 abordaban las cabeceras la situación que vivían algunos ciudadanos en la capital hispalense, hablando incluso de crisis y afirmando que las clases pasivas "están próximas a mendigar" (La Andalucía, 19 de septiembre de 1869, p. 2). La grave situación económica inundaba los periódicos, que comentaban además que esta realidad podría empeorar. Esta circunstancia sucedía mientras que "el regente se va de caza a los montes de Toledo y se continúan las obras necesarias para embellecer el palacio de D. Juan Prim" (La Andalucía, 28 de septiembre de 1869, p. 2). No parecía casual la referencia al acondicionamiento del palacete, sobre todo porque contrasta con los anteriores artículos abordando la situación de pobreza que se producía en algunas ciudades. La Andalucía dejaba para la posteridad una referencia que no pasaría desapercibida sobre todo por el contraste de ambas noticias. Si las clases bajas eran las que sufrían las consecuencias de la atmósfera inestable que se creaba durante el Sexenio Democrático, no parecía que esta afectara a todos por igual, ya que los altos cargos, entre los que se encontraba Prim, se dedicaban a otras cuestiones que dejaban entrever el escaso interés que mostraba hacia la resolución de problemas tales como la pobreza o la escasez de alimentos. Comienza el diario republicano a emprender un ejercicio de ridiculización abordando la figura del general Prim. Resulta llamativo pues, con la puesta en marcha de este pensamiento, que quien en un principio fuera defensor del pueblo y el artífice del Pacto de Ostende, ahora apareciera dándose una serie de caprichos que distaba bastante de la imagen que tenía allá por 1868 cuando estalló "La Gloriosa". Esta construcción vendría encaminada a continuar una estela donde Prim ya no era el mismo que se erigiera como uno de los salvadores del pueblo. Por lo tanto, se iniciaba la configuración de un personaje que, cuanto más se acercaba a las esferas regias, más se alejaba de los principios de la revolución.

La próxima referencia al conde de Reus la encontramos el día 9 de octubre precisamente al abordar la revista de tropas que sucedió en Madrid y a la que asistió 
Prim y el regente por aquel entonces, Serrano. Aunque es un asunto que aparece en la prensa, destacaría la visión de La Andalucía, que declaraba que "el general Prim, como acostumbran hacer los reyes con los príncipes, llevaba a su niño, el cual tuvo ocasión de distinguirse con un acto que le indicó su papá" (13 de octubre de 1870, p. 2), en alusión a un hecho que sucedió durante este acontecimiento, donde Prim pidió a Serrano que recogiese y entregase a un soldado la espada que se le había caído mientras este iba con su caballo. A la imagen de ser Prim una persona que estaba más pendiente de llevar a cabo la realización de sus pasatiempos predilectos, como la caza, en vez de preocuparse por los problemas por los que atravesaba el pueblo, habría que sumar ahora el matiz de ser un personaje que da órdenes y que trata a los demás como si estuviesen un rango por debajo de él. También es significativa la referencia hacia Serrano, quien vendría a ser un pupilo manejado por el marqués de los Castillejos.

La prensa no se centraba solamente en su faceta de ministro sino que iba más allá los meses previos a la llegada del próximo rey de España. Precisamente en este mismo artículo destaca la cabecera republicana que se le preparó a la mujer del presidente del Consejo de Ministros, a la sazón Prim, una pequeña carpa para que esta pudiera presenciar el desfile, un hecho "que no hacían ni los reyes". Por tanto, la esposa de Prim, Francisca Agüero y González, había sido objeto de un detalle, la colocación de un reducido toldo, al que ni siquiera los reyes tenían acceso, según el periódico. Si al inicio del Sexenio las referencias a Prim solo eran meras menciones y además aparecían en contadas ocasiones, ahora estas iban incrementándose y no para dar una buena imagen precisamente, sino todo lo contrario. La posición de la cabecera tricolor era más que predecible, sobre todo por la lejanía de las ideologías que Prim y el diario tenían. Así pues, cualquier detalle que pudiera sacar a relucir y que dejara al conde en mal lugar sería bienvenido para mostrar a la ciudadanía cómo era el actual presidente del Consejo de Ministros. En esta ocasión, las referencias recordaban cómo este periódico había tratado la imagen de Isabel II tras "La Gloriosa", pues precisamente sobre el dispendio cometido por la familia real exiliada se habían publicado bastantes artículos los meses posteriores. Mientras tanto, Prim se esforzaba por allanar la llegada de un rey extranjero a España convirtiéndose en su mano derecha antes incluso de que el duque de Aosta pisara el suelo de una nación que no sería fácil comandar.

Pocos días después, La Andalucía volvía a dirigir su mirada hacia Prim, en este caso formulando una serie de preguntas centradas en las reformas que se habían llevado a cabo en el ministerio de Guerra, que era su morada. "¿de dónde salen estos gastos? ¿Se han sacado las obras a subasta? ¿A qué artículo del presupuesto se aplican? ¿Están votados por las Cortes estos despilfarros?" (19 de octubre de 1870, p. 2). Nuevamente la cuestión económica se convertía en protagonista, mientras que el pueblo sufría condiciones que lo conducía hacia la pobreza. Las arcas no se encontraban en un estado óptimo y el hecho de mencionar esta cuestión no hacía sino encender los 
ánimos que ya de por sí estaban crispados, si tenemos en cuenta el marco político y social del momento. No se trataba solo de desprestigiar la figura de Prim, sino de advertir a la población de los gastos que se estaban realizando en un momento donde las arcas se encontraban en mínimos. Era también la construcción de una atmósfera donde el derroche tenía una importante presencia, significando la antesala de lo que supondría la llegada de la monarquía. ¿Se quedarían las arcas en mínimos con el duque de Aosta cuando llegara al trono? $Y$, de suceder esta situación, ¿quién sería el respondable de ello? La culpabilidad recaería sobre Prim, máximo protector de Amadeo. Si España se encontraba atravesando una situación complicada, la llegada de una nueva familia real vendría a ser la estocada definitiva a la maltrecha economía, que desde hacía tiempo venía mostrando signos de debilidad y afectaba a la población. Si además se le añade que el principal defensor de la llegada de un nuevo monarca es una persona que está realizando una serie de gastos para acondicionar, entre otros, el Ministerio de Guerra, ¿qué sucederá cuando llegue el próximo rey?

En el mes de octubre se abordaría ya la cuestión del trono. El diario tricolor hablaba de los "amantes platónicos de la monarquía" (20 de octubre de 1870, p. 2), quienes iban siendo señalados, encontrándose entre ellos, como no podía ser de otro modo, el general Juan Prim. Durante estos días la prensa abordaría este tema, intentando predecir cómo se repartirían los votos entre los candidatos en un momento donde todo parecía presagiar que las premisas promulgadas al inicio del estallido del Sexenio Democrático iban a deshacerse en medio de tanta inestabilidad como la que imperaba. Además, la recesión iba en aumento, no siendo esta una única dificultad circunscrita a un ámbito en especial sino que se trataba de una crisis "monárquica, de regencia, ministerial, de conciliación y financiera" (25 de octubre de 1870, p. 2). La Andalucía aprovechaba las divisiones existentes para fomentar la construcción de varias imágenes. Por un lado, alentar de la dificultad del asentamiento de una monarquía que tendría entre sus enemigos a un gran número de partidarios de esta forma de gobierno, pues pretendían otro candidato para el trono. Por otro, y más importante, sustentar sus opiniones sobre la idea de que la República sería el camino más fructífero para el futuro del país. La dificultad aumentaba a medida que se aproximaban los días de elección del futuro rey de España. Todas estas cuestiones empañaban el deseo de Prim. La prensa se preguntaba también si el pueblo estaba de acuerdo en la vuelta de la monarquía como forma de gobierno, considerando este objetivo como una imposición.

Entrados ya en el mes de noviembre, La Andalucía expresaba en un nuevo artículo que la monarquía, como institución, estaba abocada al fracaso, tanto que incluso no daría tiempo a que se asentase en el país. Consideraba esta una forma de gobierno imposible dadas las circunstancias actuales del momento y asegurando que terminaría desorganizándose "no precisamente por los esfuerzos republicanos, sino por los grandes obstáculos que le levanten los partidarios de dicha institución" (2 de 
noviembre de 1870, p. 2). Ahora, la cabecera tricolor afirmaba que el regreso de la monarquía se encontraría con bastantes impedimentos, tantos que incluso la abocarían al fracaso. Lo más llamativo es que, si nos atenemos a las declaraciones de este texto, los culpables de que no fructificase el desarrollo de la institución monárquica no serían los republicanos, sino que recaería en los propios defensores de la Corona. Dentro de estos se encontraba Prim, no solamente como componente de este grupo sino como el más destacable de quienes ansiaban la llegada de una familia real. Entre los impedimentos, no especificados por La Andalucía, podrían encontrarse bastantes, pero si nos atenemos a anteriores escritos de esta misma cabecera, la clave estaría en la poca unión entre los monárquicos y las diferencias existentes entre ellos y sus diferentes candidatos. De este modo, si se cumplían las expectativas del grupo monárquico, estas no alcanzarían a todos por igual, dado que cada espectro de la formación aspiraba a que terminase siendo elegido el que ellos esperaban.

Quedaba días para la votación pero no tardaría La Andalucía en hablar de la candidatura del duque de Aosta, asegurando que "no le liga (...) con el país ningún vínculo, ninguna relación; no conoce nuestras costumbres, nuestras leyes, nuestras instituciones y carácter, es menos que un rey de partido, es un rey impuesto por un solo hombre" (6 de noviembre de 1870, p. 2). Este hombre, es sin duda, Juan Prim. Sin mencionarlo, era más que conocida la esperanza que el conde de Reus tenía depositada en el hijo de Víctor Manuel II de Italia. El hecho de que la cabecera haga hincapié en que el duque de Aosta era una imposición, se erige como una característica quizá sobresaliente por encima de las anteriormente citadas. Porque ya no se trataba solo de la implantación de la monarquía sino que además el conde de Reus cometía un doble abuso al cumplirse su deseo de que fuera Amadeo de Saboya quien ocupase el trono español. Era nada menos que un atropello el que se cometía, incluso más grave que otros, pues esta exigencia iba en contra de los principios que se habían proclamado en septiembre de 1868.

Entrado el mes de noviembre La Andalucía critica a aquellos que han permitido que la monarquía vuelva a estar de actualidad, añadiendo "Prim, Serrano, Sagasta, Figuerola; el país reconoce todo el mal que le habéis hecho y os desdeña con toda la grandeza de su majestad (...). Rivero, Martos, Moret, vosotros, vosotros sois los sacrificadores de la libertad" (15 de noviembre de 1870, p. 2). El diario culpaba a una serie de políticos revolviéndose contra ellos en vez de hacerlo contra Amadeo de Saboya. Al fin y al cabo, la figura del duque de Aosta no era más que una de las candidaturas que se barajaban y que hundía sus raíces en la voluntad de un determinado espectro político que confiaba en que la Corona fuese la sanación de todas las dificultades. Estos consideraban que con una nueva familia real vendrían a solucionarse esta serie de problemas que, aunque existentes en distintos ámbitos, tales como la política o la economía, todos se interconectaban entre sí, confluyendo en una grave crisis que 
tambaleaba los cimientos asentados sobre los principios proclamados en septiembre de 1868.

El general tenía ahora enfrente un problema mayor. Además de contar con varios grupos políticos en su contra, capitaneados por los republicanos principalmente, se encontraba con una notable división en el seno de los monárquicos, ya que también tendría en contra a compañeros que pertenecían a su mismo grupo. Estos se encontraban encabezados fundamentalmente por montpensieristas, carlistas y esparteristas, teniendo a su favor el apoyo de los aoistas, que era un número bastante reducido. Se avistaba por lo tanto una compleja tarea en la que intentar calmar los ánimos con el objetivo de reducir la crispación existente y convencer de que Amadeo de Saboya sería la mejor elección. En la capital hispalense, la candidatura defendida por Prim no tenía un órgano que la defendiera, tal y como se encargaba La Andalucía de dejar constancia en sus páginas (17 de noviembre de 1870, p. 2). Este diario criticaba también las propuestas que sostenían las otras cabeceras sevillanas, erigiéndose como un diario mordaz y crítico en esta cuestión, justificada por su férrea oposición a la Corona. Precisamente en la capital hispalense, la mayoría de la coalición sevillana apostaba por la candidatura del duque de Montpensier (Arias, 1990: 75). Además, su defensa de la República es patente sus artículos provenientes de las agencias de noticias así como los propios, apostaban fuertemente por rechazar la monarquía y continuar defendiendo la República. La elección de un futuro monarca era una decisión que se convertía en un obstáculo destacable para el desarrollo de la revolución, idea que La Andalucía continuaba repitiendo para alertar al pueblo de que lo que se estaba llevando a cabo era la muerte de aquel proceso iniciado en septiembre de 1868 . Y, entre aquellos culpables, destacaba la figura de Prim, no ya solo porque apostaba fuertemente por la Corona sino porque además había sido elegido el pretendiente que llevaba defendiendo desde hacía tiempo.

Referente al día de la votación en la que salió elegido el futuro rey de España, La Andalucía afirmaría posteriormente que "ese día ha puesto término a la Revolución colocando sobre su huesa la pesada losa de una monarquía extranjera" (20 de noviembre de 1870, p. 2). Soplaban tiempos de cambio y la cabecera defendía su marcado carácter ideológico, desarrollando artículos en los que criticaba a todos aquellos defensores de la monarquía, especialmente a Prim, y también a una familia que todavía no había pisado suelo español. Sin embargo, el hecho de dirigirse a Amadeo de Aosta también era una manera de alertar a la sociedad sobre lo que sucedería, argumentando por ejemplo el gasto, bajo el punto de vista del diario "innecesario", que se produciría dentro de poco. Y estos aspectos, claramente apuntaban a Prim, valedor del citado pretendiente y protector máximo de su figura.

Posteriormente las informaciones versaban sobre si Amadeo de Saboya aceptaría o no la corona, siendo confusas, ya que nos encontramos aquellas que apuestan por un "si" 
del futuro monarca y las que comentaban la negativa de querer ser el próximo representante de la Corona española. El diario añadiría relativo a esta última actitud "muy cruel la conducta del presunto monarca para con sus improvisados súbditos cimbros y progresistas" (24 de noviembre de 1870, p. 2).

No sería Prim quien viajase a Italia para entrevistarse con Amadeo de Saboya, sino Zorrilla, quien también sería objeto de las críticas de la citada cabecera en la que hemos basado este análisis. La próxima referencia a Prim se inserta ya el mes siguiente, a finales de diciembre. La Andalucía lo acusaba directamente de "apresurar a todo trance, salga lo que saliere, la venida del desgraciado de Amadeo" (24 de diciembre de 1870, p. 2). No se sabía con exactitud qué podría suceder con la llegada del hijo de Víctor Manuel II pero el diario republicano nos mostraba a quien era su mayor defensor como una persona que, a pesar de los problemas que este proyecto podría acarrear, se empeñaba en que se cumpliese el objetivo que desde hace tiempo venía defendiendo. En esta ocasión, Prim aparece como quien intenta mantener bajo control el desarrollo de los acontecimientos sobre la llegada del futuro Amadeo I, pretendiendo a toda costa que se llevaran a cabo los movimientos concernientes a este aspecto de la manera más rápida posible, dibujando un apresuramiento tal que no podía entenderse por parte de la prensa, mayoritariamente la republicana. El desconcierto era tal que las informaciones sobre el apartado de la Corona eran difusas, aunque La Andalucía encontraba en Prim el principal responsable de este hecho. De este modo, lo acusaba de hacer todo lo posible para que el duque de Aosta llegara al trono español, a pesar de las dificultades, en la mayor brevedad posible.

\subsection{La muerte del general Prim}

El día 30 de diciembre desembarcaría Amadeo de Saboya en Cartagena, pero anteriormente, el día 27 de diciembre, ocurriría un hecho que sin duda marcaría el devenir de los acontecimientos y que afectaría considerablemente al establecimiento y posterior desarrollo de los futuros miembros de la monarquía en España. Semanas antes ya habían comenzado los preparativos para recibir al futuro aspirante que ocuparía el trono, el cual quedó vacante tras la marcha de los Borbones. Este ambiente contrastaría de lleno con un suceso que haría más complicado aún el asentamiento del duque de Aosta y sus más allegados.

Tras terminar su jornada de trabajo, salía Prim del Parlamento dispuesto a subirse en su berlina y dirigirse hacia su domicilio, realizando un recorrido que se producía casi diariamente, por lo que era más que conocido el trayecto que habitualmente realizaba. Tras pasar por la calle del Turco - actual Marqués de Paradas - tres individuos atentaron contra él. Tres días más tarde terminaría falleciendo, concretamente el 30 de diciembre. Aunque existieron varias teorías sobre este 
acontecimiento, cobró protagonismo aquella que apostaba por mostrar este suceso como una medida conspiración donde detrás se encontraba el mismísimo duque de Montpensier, eterno aspirante al trono español.

La figura del general Prim se encuentra tan unida a la de Amadeo de Saboya que incluso se afirmó que la elección del nuevo rey fue clave del asesinato del conde de Reus. Aunque no faltaron otros indicios, es innegable que este asunto supuso un ingrediente notable en el acaecimiento que puso fin a la vida del general:

En aquella fecha el conde de Reus tenía ya asegurada la candidatura de Amadeo de Saboya al trono español, y es más que probable que tratara de desembarazar a la futura monarquía de un lastre tan enorme como el que suponía la guerra en tierras cubanas. Deshacerse de Cuba abría todo un campo de posibilidades en la política española, en particular en el terreno militar y social. ¿Se conoció esta decisión en La Habana y en Madrid y provocó alguna reacción contra la vida de Prim? No faltan quienes piensan que ambos acontecimientos tuvieron alguna vinculación. (De Diego, 2003: 366)

La muerte del general Prim vendría a ser un acontecimiento que crearía un auténtico terremoto en el campo político, ya que después de su fallecimiento el Partido Progresista terminaría dividiéndose en dos nuevos partidos dinásticos que tendrían sus posteriores enfrentamientos. Por un lado, situado en el flanco izquierdo, nos encontraríamos con el radical, capitaneado por Ruiz Zorrilla; en el otro bando, el constitucional, representado por Sagasta (Seoane y Saiz, 1983: 242).

El día 3 de enero de 1871 abría La Andalucía su edición abordando el acontecimiento de la muerte de Prim, declarando:

¡Qué coincidencia! (...) murió Prim, también murió definitivamente la Asamblea, que bien o mal era lo único que ya personificaba aquella gran Revolución, grande y magnífica en los primeros momentos, magnánima y generosa cuando en toda Europa se la aplaudía; mezquina, raquítica, torpe y baladí cuando entregada el egoísmo de unos pocos vino a rematar en un triste asesinato y en una deplorable situación (3 de enero de 1871, p. 1).

La cabecera comentaba cómo se había producido este atentado así como los detalles que por ahora se conocían. Un asunto de tales dimensiones, como no era de otra manera, aparecía en la primera página de otros diarios, dando a conocer cómo se había llevado a cabo un asalto que cambiaría el rumbo de la España más inmediata. Sin embargo, en el caso de La Andalucía, la opinión se intercalaba con la información que ofrecían. Como se inserta líneas arriba, el diario argumenta que muriendo el general Prim lo hacía también la revolución comenzada en septiembre de 1868 , teniendo además un final que nadie se esperaba. A ojos de La Andalucía, la muerte de Prim venía a ser el punto y final de un proceso que había comenzado varios años atrás, que 
había sido recibida clamorosamente por el pueblo y que después había ido entrando en un estado de degradación que terminaba a finales del año de 1870 . Si precisamente fue él quien potenció con el Pacto de Ostende la caída de los Borbones, según La Andalucía, Juan Prim se llevaba lo poco que quedaba de la ya maltrecha y dañada revolución.

A pesar de que Amadeo de Saboya llegaba a España con pocos apoyos, contaba con la defensa de un importante militar y político destacado en nuestra historia contemporánea. Sin embargo, el fallecimiento del principal defensor de la candidatura del hijo de Víctor Manuel II venía a dar una estocada que producía una herida de muerte irreparable. No se encontraría Amadeo con un escenario más desolador ya que "los radicales Iloraban la muerte del general Prim; el pueblo no era monárquico; la aristocracia no era dinástica y tenía vueltos los ojos al palacio en el que vivían en el destierro los príncipes de la casa de Borbón" (Nogués, 1895: 43).

Abordada en profundidad la situación desencadenada tras la muerte de Prim, los diarios pasaban página y el principal promotor de la llegada de Amadeo de Saboya quedaba ya en el pasado. Ahora, las críticas que vertía La Andalucía se dirigirían hacia otros políticos, tales como Zorrilla o Sagasta, encontrando también en la figura del duque de Aosta un puntal importante sobre el que cimentar un odio que recaía en él por la única razón de ser el rey que ocupaba el trono de España.

\section{Conclusiones}

Como hemos podido comprobar, una figura tan destacada como es la del general Prim durante parte del Sexenio Democrático, no podía pasar desapercibida para los diarios de la época, concretamente para los hispalenses. En el caso de La Andalucía, hemos observado cómo el interés hacia la figura del conde de Reus iba incrementándose a medida que lo hacía también la importancia del mismo dentro del seno político. El pronunciamiento acaecido en Cádiz el 18 de septiembre de 1868 iniciaba una nueva época que tenía su reflejo en varias vertientes. Entre ellas, y la más importante para el desarrollo de este análisis, destaca sobremanera la libertad de imprenta que abre un camino sin precedentes en la historia del periodismo español, al existir una expresión libre donde tuvieran cabida los más variopintos diarios con sus respectivas ideologías.

Este hecho es significativamente destacable para palpar el sentir de la prensa de aquel entonces sobre los diversos cambios que se producían. Desde el estallido de la revolución, el general Juan Prim, uno de los artífices de este hecho, aparece en las páginas de La Andalucía. Tras la marcha de los Borbones, este diario se declara abiertamente republicano y ensalza la figura del general destacando que con este 
capítulo se inicia una nueva época que el diario tricolor abraza. La Andalucía alaba a todos aquellos que han hecho posible que una incipiente etapa vaya asentando los pilares de un nuevo futuro, encontrándose en este campo Juan Prim.

Posteriormente, la figura del general irá pasando desapercibida, aunque La Andalucía, que se convertirá paulatinamente en un órgano defensor de la República, hará indirectamente referencia a él cuando hable sobre el partido del que Prim formó parte. Tras la puesta en marcha de la búsqueda de un pretendiente para el trono, la cabecera de Francisco María Tubino se centrará en combatir las candidaturas de los diarios que hay en Sevilla, y entre los que no se encuentra ninguno que avale la propuesta de Amadeo de Saboya. Sin embargo, cuando el duque de Aosta vaya ganando adeptos, el diario no dejará pasar la oportunidad para centrarse en quien es el máximo artífice de esta propuesta. Precisamente aprovechando la época tan difícil donde las arcas se encontraban en mínimos, el republicano diario utiliza esta vertiente para ir en contra de Prim y mostrarlo ante la sociedad como una personalidad que hace uso de un dinero que podría aprovecharse para paliar los efectos tan devastadores que estaban dejando los últimos cambios y que aumentaban los índices de pobreza.

Utilizado el aspecto económico para incendiar los ánimos de la sociedad ante la llegada de un futuro rey, La Andalucía arroja la característica de encontrarnos ante una persona inflexible en sus pensamientos y obcecada en la búsqueda de alguien que ocupe el trono español lo antes posible, presentándonos a Amadeo de Saboya como la imposición de un exigente Prim que quiere a toda costa que el solio se ocupe en el menor tiempo posible. El diario también sabría aprovechar la división en el seno de los monárquicos. La estrategia comunicativa de La Andalucía encontraría en medio de estas diferencias la oportunidad de criticar a Prim y su apoyo a Amadeo I para poder influir en la construcción de una opinión favorable a la república.

De haber sido ensalzado al comienzo del Sexenio Democrático, ahora era vilipendiado por el órgano republicano, el cual lo acusaba de haber sacrificado la libertad nacida en aquel septiembre de 1868 empeñándose en traer a un rey extranjero. Ahora Prim se presentaba como un traidor que había cambiado su rumbo hasta colocarse en el otro extremo, siendo uno de los principales enemigos de un sistema que buscaba demoler. Finalmente, las críticas hacia Prim finalizan a principios de 1871, que es cuando La Andalucía aborda la muerte del general, mostrando su rechazo absoluto hacia este atentado. En esta ocasión, el diario tricolor declara que Juan Prim se ha llevado con él los ideales de la revolución. El hombre que dio pie a una nueva etapa, se marchaba, según el periódico de Tubino, trasladando con él lo que comenzó un par de años antes. La Andalucía continuaría su discurrir acrecentando su republicanismo, y centrando ahora sus críticas en otros políticos y en Amadeo de Saboya, por lo que la empresa edificada por Prim seguiría teniendo sus réplicas por parte de este diario. 


\section{Referencias bibliográficas}

ÁLVAREZ, F. (2008): El General Prim y "La Gloriosa" Revolución de 1868, tesis doctoral.

ARIAS CASTAÑÓN, E. (1987): “Ordenamiento provincial, liberalismo y prerregionalismo andaluz. Notas del periódico La Andalucía de Sevilla (1857-1864)", en Actas del II Congreso sobre el Andalucismo Histórico. Sevilla, pp. 383-399.

- (1989): "Francisco María Tubino y el diario sevillano La Andalucía ante la Primera República: patria y federalismo", en Actas del IV Congreso sobre el Andalucismo Histórico. Cádiz, pp. 263-280.

- (1990): “Expectativas y limitaciones de la democracia en la Sevilla del Sexenio (1868-1874)", en Espacio, Tiempo y Forma, tomo III, pp. 65-84.

- (1995): "La prensa política de Sevilla en el Sexenio Democrático (1868-1874)", en Información y Ciencia, Sevilla, Universidad de Sevilla, pp. 39-45.

- (2001): "La prensa de Sevilla ante la Revolución de 1868", en Comunicación, historia y sociedad. Homenaje a Alfonso Braojos. Sevilla, Universidad de Sevilla, pp. 171-192.

- (2010): La Revolución de 1868 en Sevilla. Sevilla, ayuntamiento de Sevilla.

ARTOLA, M. (1975): Partidos y programas políticos, 1808-1936, Madrid, Aguilar.

BOLAÑOS, M. C. (2014): El reinado de Amadeo de Saboya y la monarquía constitucional, Madrid, UNED.

BOOKCHIN, M. (2001): Los anarquistas españoles: los años heroicos, 1868-1936, Valencia, Numar.

CHECA GODOY, A. (2006): El ejercicio de la libertad. La prensa española en el Sexenio Revolucionario (1868-1874), Madrid, Biblioteca Nueva.

COMELLAS, J. L. (1999): Isabel II: Una reina y un reinado, Barcelona, Ariel.

DE DIEGO, E. (2003): Prim, la forja de una espada, Barcelona, Planeta.

DOMíNGUEZ LEÓN, J. (1985): "Las finanzas y la crisis de 1868 en Sevilla. Una aproximación estructural", en Actas del III Congreso de Historia de Andalucía. Historia Contemporánea. Tomo III, Córdoba, pp. 133-138.

GIMÉNEZ Y GUITED, F. (1860): Historia militar y política del General Juan Prim, Madrid, Librería de D. Emilio Font.

GUEREÑA, J. L. (1982): Metodología de la historia de la prensa española, Madrid, Siglo XXI, Madrid, pg. 86. 
GUICHOT Y PARODY, J. (1885): Historia de la ciudad de Sevilla y pueblos importantes de su provincia desde los tiempos más remotos hasta nuestros días. Tomo $\mathrm{V}$, Sevilla, imp. y lit. de José María Ariza, página 252.

JOVER, J. M. (1968): “1868. Balance de una revolución” en Cuadernos para el diálogo, no 59-60, 1968, pg. 15.

LORENZO, C. (1969): Los anarquistas españoles y el poder: 1868-1869, París, Ruedo Ibérico.

MARTÍ GILABERT, F. (2007): La Primera República Española, (1873-1874), Madrid, Rialp.

NOGUÉS, E. J. (1895): Historia crítica de la Restauración borbónica en España (veinticinco años de historia contemporánea), Tomo I, Barcelona, Casa Editorial de Román Gil.

PIZARROSO QUINTERO, A. (2010): "El periodismo en el primer tercio del siglo XX", en Arbor. Ciencia, Pensamiento y Cultura, nCLXXXVI, junio 2010, pp. 45-54.

RUBIO, C. (1868): Historia filosófica de la Revolución española de 1868, tomo III, Madrid, imprenta de M. Guijarro, pg. 82.

SEOANE, M. C. y SAIZ, M. D. (1983): Historia del periodismo en España, Madrid, Alianza.

VARELA, J. (2006): “La monarquía en las Cortes y en la Constitución de 1869", en Historia Constitucional, no 7, páginas 209-228. 